\title{
Evidence of higher intramyocellular fat among normal and overweight Indians with prediabetes
}

\author{
S. Sucharita ${ }^{1} \cdot$ R. Pranathi ${ }^{1}$ - M. Correa ${ }^{1}$ P. Keerthana ${ }^{2}$ - L. J. Ramesh ${ }^{1} \cdot$ G. Bantwal ${ }^{1}$ - H. M. Venkatappa ${ }^{3}$. \\ K. P. Mahadev ${ }^{1}$ - T. Thomas $\mathbb{D}^{1} \cdot$ R. J. Bosch ${ }^{4}$. S. D. R. Harridge ${ }^{5}$ A. V. Kurpad ${ }^{1}$
}

Received: 1 August 2017 / Revised: 16 January 2019 / Accepted: 22 January 2019 / Published online: 6 February 2019

(c) The Author(s) 2019. This article is published with open access

\begin{abstract}
Background The rise in prevalence rates of Type 2 Diabetes among Indians is well recognized. The research focus has been primarily to understand the changes in insulin sensitivity and beta cell dysfunction among Indians with Type 2 Diabetes. However, no data are available on the role of peripheral tissue, in particular intramyocellular lipid (IMCL) content and its impact on glucose homeostasis among Indians with prediabetes.

Methods 28 male subjects (20-40 year) were studied. 13 with prediabetes (BMI ranging from $25.4 \pm 2.9 \mathrm{~kg} / \mathrm{m}^{2}$ ) and 15 controls (BMI ranging from $24.6 \pm 2.8 \mathrm{~kg} / \mathrm{m}^{2}$ ) were recruited. Body composition by dual energy X-ray absorptiometry (DXA), insulin sensitivity, insulin secretion rates were derived using the minimal model of C-peptide secretion and kinetics rates and skeletal muscle strength of the lower limb (quadriceps) was assessed using Isokinetic dynamometry. From muscle biopsy samples of the vastus lateralis, IMCL fat content (Oil red O staining) was determined.

Results The prediabetes group were older compared to controls $(P<0.01)$, but had similar BMI. The muscle to fat ratio, plasma Insulin, C peptide, HOMA-IR and HOMA \% B were also comparable between the groups. IMCL fat content (\%) was significantly higher in the prediabetes group compared to controls $(7.0 \pm 0.7 \%$ vs. $2.0 \pm 0.3 \%, P<0.01)$. This difference persisted even after controlling for age. Overall the IMCL fat content $(\%)$ was positively and significantly associated with HbA1c $(r=0.76, P<0.01)$. HOMA-IR was significantly correlated with central (android, trunk) adiposity $(\mathrm{kg})$ $(r=0.71, P<0.01)$ but not with IMCL $(\%)$.

Conclusions This is the first direct evidence of existence of significantly higher lipid levels within skeletal muscle cells among normal and overweight young Indians with prediabetes. However, there was no association between IMCL and HOMA-IR among the prediabetes group.
\end{abstract}

S. Sucharita

sucharita@stjohns.in

1 Department of Physiology, Pathology, Biostatistics, Orthopaedics and Endocrinology, St John's Medical College and Hospital, Bangalore, Karnataka, India

2 School of Information Sciences, Manipal Academy of Higher Education, Manipal, India

3 Kanva Diagnostics Services Pvt Ltd, Rajajinagar, Bangalore, India

4 Department of Biostatistics, Harvard TH Chan School of Public Health, Boston, MA, USA

5 Centre for Human and Applied Physiological Sciences, King's College London, London, UK

\section{Introduction}

Asian Indians are said to have a greater propensity for a phenotype characterized by an excessive accumulation of fat, even with a normal body mass index (BMI) $\left(\mathrm{kg} / \mathrm{m}^{2}\right)$, which has been termed "metabolically obese" [1,2]. In turn, Asian Indians are thought to be at a greater risk of becoming profoundly insulin resistant; suggesting the possibility that insulin resistance in this population is related to adiposity [3]. Central adiposity (excess fat in the central regions of the body i.e., trunk, android fat) has been associated with insulin resistance $[4,5]$. But the role of ectopic fat, an excess of adipose tissue in locations that are not classically associated with adipose tissue storage has not been explored among the Indian population, in particular in regard to lipid accumulation within skeletal muscle fibers (intramyocellular lipid content, IMCL). Several mechanisms have been 
proposed to explain the tendency for an individual to deposit adipose tissue in ectopic versus non-ectopic sites [6]. For example, it is possible that a positive energy balance could lead to an excess of free fatty acids, which are initially stored subcutaneously. Subsequently, free fatty acids shift to ectopic sites or non-adipose tissue such as the heart, skeletal muscle, as well as the vasculature, once the storage capacity of subcutaneous adipose tissue is exhausted [7]. Since this fat storage in non-adipose tissue is independent of more generalized adiposity, it is difficult to establish robust associations with insulin resistance [8]. This is particularly relevant among Indians, since the susceptibility to develop Type 2 Diabetes is increasing, despite the majority of the Indian population not being obese [9-11].

A relationship between IMCL and insulin resistance, though demonstrated in Caucasians, has not been established among Asians with Type 2 Diabetes [12, 13]. In addition there is little information about IMCL among normal and overweight resident Indians, particularly those with prediabetes. While ectopic fat accumulation has been investigated in Indians with Type 2 Diabetes using magnetic resonance spectroscopy (MRS), there have been no reports of cellular lipid accumulation in skeletal muscle in this population $[14,15]$. Therefore, in order to provide further insight into the mechanisms leading to Type 2 Diabetes among Indians, the present study aimed to undertake a histological and quantitative study of IMCL in the quadriceps muscle of normal and overweight Indians with prediabetes and to evaluate the association between glycemic control and IMCL in this population.

\section{Methods}

\section{Participants}

Twenty eight young adult males between the age of 20-40 year (13 newly diagnosed prediabetes and 15 healthy controls) with BMI $18.5-30 \mathrm{~kg} / \mathrm{m}^{2}$ according to WHO criteria [16], were recruited in and around the St John's Medical College and Hospital in Bangalore, and through advertisements. The number of normal weight (BMI of 18.5-24.9 $\mathrm{kg} / \mathrm{m}^{2}$ ) with Prediabetes were, $n=8$ and controls were, $n=$ 10. The overweight (BMI of $25-29.9 \mathrm{~kg} / \mathrm{m}^{2}$ ) individuals with prediabetes were, $n=5$ and controls, $n=5$.

The American Diabetes Association Expert Committee criteria [17] based on two-sample OGTT, where plasma glucose (GOD POD method, Beckman Coulter AU480, Japan) and glycosylated hemoglobin (HPLC method, BioRad, Model Variant Turbo II, India) values were used to diagnose prediabetes (dysglycemia was detected by either fasting blood sugar, $101-125 \mathrm{mg} / \mathrm{dl}$, postprandial sugar, $141-199 \mathrm{mg} / \mathrm{dl}$ or HbA1c, 5.7-6.4\%). If one of the above criteria was satisfied the subject was considered prediabetic. For the control group the following criteria was used: fasting blood sugar $<101 \mathrm{mg} / \mathrm{dl}$, postprandial sugar, $<141$ $\mathrm{mg} / \mathrm{dl}$ and $\mathrm{HbAlc},<5.7 \%$. All subjects underwent serum lipid profiling, including serum cholesterol, high density lipoprotein (HDL), low density lipoprotein (LDL) and triglyceride estimations using a Chemiluminescence Immunoassay (Siemens, Model EXL with LM 1 \& 2, Germany). Subjects with any chronic disease (i.e., hypertension, tuberculosis, cancer, chronic renal failure, and ischemic heart disease), anemia, peripheral neuropathy, muscular dystrophies, joint injuries, weight loss greater than $2 \mathrm{~kg}$ in the past 6 months were excluded from the study. Physical activity levels (PAL) were calculated based on a physical activity questionnaire [18]. Sample size was based on the previous results [19], which compared IMCL fat content between non obese and obese Type 2 Diabetes, to detect a difference of $10 \%$ with a $80 \%$ power and a $5 \%$ level of significance, the number of subjects in each group was calculated to be $n=13$. All protocols were approved by the Institutional Review Board, St John's National Academy of Health Sciences, Bangalore, India and written informed consent was obtained from all participants prior to the study.

\section{Metabolic status}

An oral glucose tolerance test was performed to derive indices of beta cell function and insulin sensitivity. The subjects were given $1 \mathrm{~g} / \mathrm{kg}$ of glucose mixed in $300 \mathrm{ml}$ of water, to drink. Venous blood samples were obtained at following time points: before the oral glucose ingestion at -10 and $-5 \mathrm{~min}$, and after, at $5,10,15,20,30,45,60$, 90,120 min $[20,21]$. Plasma glucose was estimated by the GOD-POD method (Beckman Coulter AU480, Japan) and plasma Insulin and C-peptide levels were measured by electrochemiluminescence (Elecsys 2010, Roche Diagnostics, Manheim, Germany). The intra-assay CV for insulin and C-peptide was 3\% and 3.5,\% respectively, while the inter-assay $\mathrm{CV}$ for insulin and $\mathrm{C}$-peptide was $1.3 \%$ and $1.0 \%$ respectively. The minimal model of C-peptide secretion and kinetics rates were used to derive insulin secretion rates, as described earlier [22]. Insulin resistance, secretion and beta cell function (HOMA-IR and HOMA-\% B) were assessed by the homeostatic method using standard formulae for calculation [23].

\section{Body composition}

All the subjects underwent anthropometric assessment. This included weight recorded in minimal clothing to the nearest $0.1 \mathrm{~kg}$, using a digital scale (Salter digital scale, 9069 PK3R,Tonbridge, UK) and height to the nearest $0.1 \mathrm{~cm}$, 
Table 1 Descriptive data of prediabetes and control group

\begin{tabular}{|c|c|c|}
\hline & Prediabetes $(n=13)$ & $\begin{array}{l}\text { Controls } \\
(n=15)\end{array}$ \\
\hline Age (years) & $38.9 \pm 10.6 * *$ & $25.3 \pm 5.4$ \\
\hline Height (m) & $1.7 \pm \pm 0.04$ & $1.7 \pm 0.06$ \\
\hline Weight (kg) & $73.9 \pm 10.6$ & $70.8 \pm 9.5$ \\
\hline Body mass index $\left(\mathrm{kg} / \mathrm{m}^{2}\right)$ & $25.4 \pm 2.9$ & $24.6 \pm 2.8$ \\
\hline Body Fat $\%$ & $29.4 \pm 6.6$ & $29.5 \pm 7.5$ \\
\hline Lean body mass $(\mathrm{kg})$ & $49.7 \pm 6.5$ & $47.1 \pm 5.5$ \\
\hline $\begin{array}{l}\text { Appendicular muscle } \\
\text { mass }(\mathrm{kg})\end{array}$ & $31.5 \pm 3$ & $30.6 \pm 4.4$ \\
\hline Muscle-to-fat ratio & $2.6 \pm 0.8$ & $2.6 \pm 1.2$ \\
\hline Waist-to-Hip ratio & $0.8 \pm 0.2$ & $0.7 \pm 0.3$ \\
\hline Central adiposity (kg) & $14.4 \pm 5.1$ & $12.9 \pm 5.3$ \\
\hline \multicolumn{3}{|l|}{ Biochemistry } \\
\hline Serum cholesterol (mg/dl) & $172 \pm 36.7$ & $182.5 \pm 33.8$ \\
\hline HDL (mg/dl) & $38.7 \pm 12.5$ & $40.3 \pm 10.9$ \\
\hline LDL (mg/dl) & $120.1 \pm 29.5$ & $124.2 \pm 29.8$ \\
\hline $\begin{array}{l}\text { Serum triglycerides } \\
(\mathrm{mg} / \mathrm{dl})\end{array}$ & $108.7 \pm 71.2$ & $128.4 \pm 65.5$ \\
\hline HbA1c $(\mathrm{g} \%)$ & $5.9 \pm 0.3 * *$ & $5.4 \pm 0.2$ \\
\hline Fasting Glucose (mg/dl) & $101.1 \pm 10.9 * *$ & $90.8 \pm 6.4$ \\
\hline $\begin{array}{l}\text { Post prandial blood glucose } \\
(\mathrm{mg} / \mathrm{dl})\end{array}$ & $112.8 \pm 36.3 * *$ & $88.6 \pm 18$ \\
\hline Basal Insulin $(\mu \mathrm{U} / \mathrm{ml})$ & $11.4 \pm 4.9$ & $10.5 \pm 3.4$ \\
\hline Basal C Peptide (ng/ml) & $2.7 \pm 0.9$ & $2.4 \pm 0.9$ \\
\hline $\begin{array}{l}\text { Peak Insulin secretion rates } \\
\left(\mathrm{pmol} / \mathrm{min} / \mathrm{m}^{2}\right)\end{array}$ & $274.7 \pm 258.7$ & $599.7 \pm 812$ \\
\hline HOMA \% B & $103.5 \pm 50.4$ & $114.9 \pm 25.2$ \\
\hline HOMA-IR & $1.5 \pm 0.6$ & $1.4 \pm 0.4$ \\
\hline \multicolumn{3}{|c|}{ Muscle strength and physical activity } \\
\hline Physical activity level & $1.6 \pm 0.2$ & $1.6 \pm 0.2$ \\
\hline $\begin{array}{l}\text { Muscle strength Isometric } \\
\text { lower limb }(\mathrm{Nm} / \mathrm{kg})\end{array}$ & $3.9 \pm 0.9$ & $4.1 \pm 1.1$ \\
\hline $\begin{array}{l}\text { Muscle strength Isokinetic } \\
\text { lower limb }(\mathrm{Nm} / \mathrm{kg})\end{array}$ & $2.9 \pm 0.7$ & $3.1 \pm 0.9$ \\
\hline
\end{tabular}

Data represented as mean $\pm \mathrm{SD}$

$* * P<0.01$

using a Stadiometer (Holtain, Crymych, UK). The waist and hip circumferences were measured using a standard nonstretchable tape measure, at the narrowest point between the iliac crest and ribcage (waist) and at the level of the greater trochanter (hip).

Body composition was assessed using DXA (Model DPXMD 7254, Lunar Corporation, Madison, WI). The mass of lean soft tissue, fat, and bone mineral for both the whole body and specific regions were measured. The central adiposity included fat $(\mathrm{kg})$ trunk including android region. The trunk region included the neck, chest, abdominal and pelvic areas. Its upper perimeter was the inferior edge of the chin and the lower borders intersected the middle of the femoral necks without touching the brim of the pelvis. The android region was the area between the ribs and the pelvis, and was totally enclosed by the trunk region. Appendicular lean soft tissue (ALST) was equivalent to the sum of lean soft tissue in both the right and left arms and legs was also measured [24]. Appendicular lean muscle index (ALMI) was derived using the following equation ALMI = Skeletal muscle appendicular muscle mass $/ \mathrm{Ht}^{2}$ which has been described earlier [25].

\section{Muscle strength assessment}

Skeletal muscle strength of the knee extensors (quadriceps) was assessed using Isokinetic dynamometry (Kin Com AP1, Chattanooga Group, Tennessee, USA). Subjects were tested for isometric and isokinetic knee extensor strength. The best of three maximal voluntary isometric contractions for knee extension with the knee extended 30 degrees from the 90 degree flexed position and dynamic (isokinetic) peak torque (60 degree/s) were used for analysis. Subjects were provided with a rest interval of 2-3 min between each contraction and $5 \mathrm{~min}$ rest between each velocity. Peak torque data derived was normalized to appendicular muscle mass of the respective limb $(\mathrm{Nm} / \mathrm{kg})$ [26] derived from the DXA scan.

\section{Skeletal muscle biopsy and assessment of intramyocellular Lipid}

A skeletal muscle biopsy was taken from the middle part of the vastus lateralis by an orthopedic surgeon. After local anesthesia (2\% lignocaine hydrochloride- Neon Laboratories Limited, Andheri, Mumbai, India), a small incision was made through the skin and the fascia, $\sim 15 \mathrm{~cm}$ above the patella. A $5 \mathrm{~mm}$ Bergström needle (Dixon's Surgical Instruments Ltd., Wickford, UK) was inserted through the incision to a depth of about $2 \mathrm{~cm}$ under the fascia, and a muscle biopsy was obtained with addition of applied suction [27]. Muscle biopsies were rapidly trimmed of visible connective tissue and blotted free of blood. Small pieces of muscle were oriented to get transverse sections and were flash frozen in isopentane, precooled in liquid nitrogen. Ten micrometer cryosections were obtained at $-20{ }^{\circ} \mathrm{C}$ (Leica CM1520, Germany) and mounted on glass slides. The sections were air-dried for $15 \mathrm{~min}$, rinsed in $60 \%$ absolute propylene glycol for $5 \mathrm{~min}$, immersed in a double filtered working solution of Oil Red $\mathrm{O}$ for $10 \mathrm{~min}$ and differentiated in $85 \%$ propylene glycol for $1 \mathrm{~min}$. After a brief wash in distilled water, the sections were air dried, mounted in pure glycerol and the edges sealed [28]. Histology images were digitally captured (Olympus CCD, Model DP26, and Tokyo, Japan). Five contiguous fields $(40 \times)$ of view within the biopsy section that were free of artifacts were analyzed 

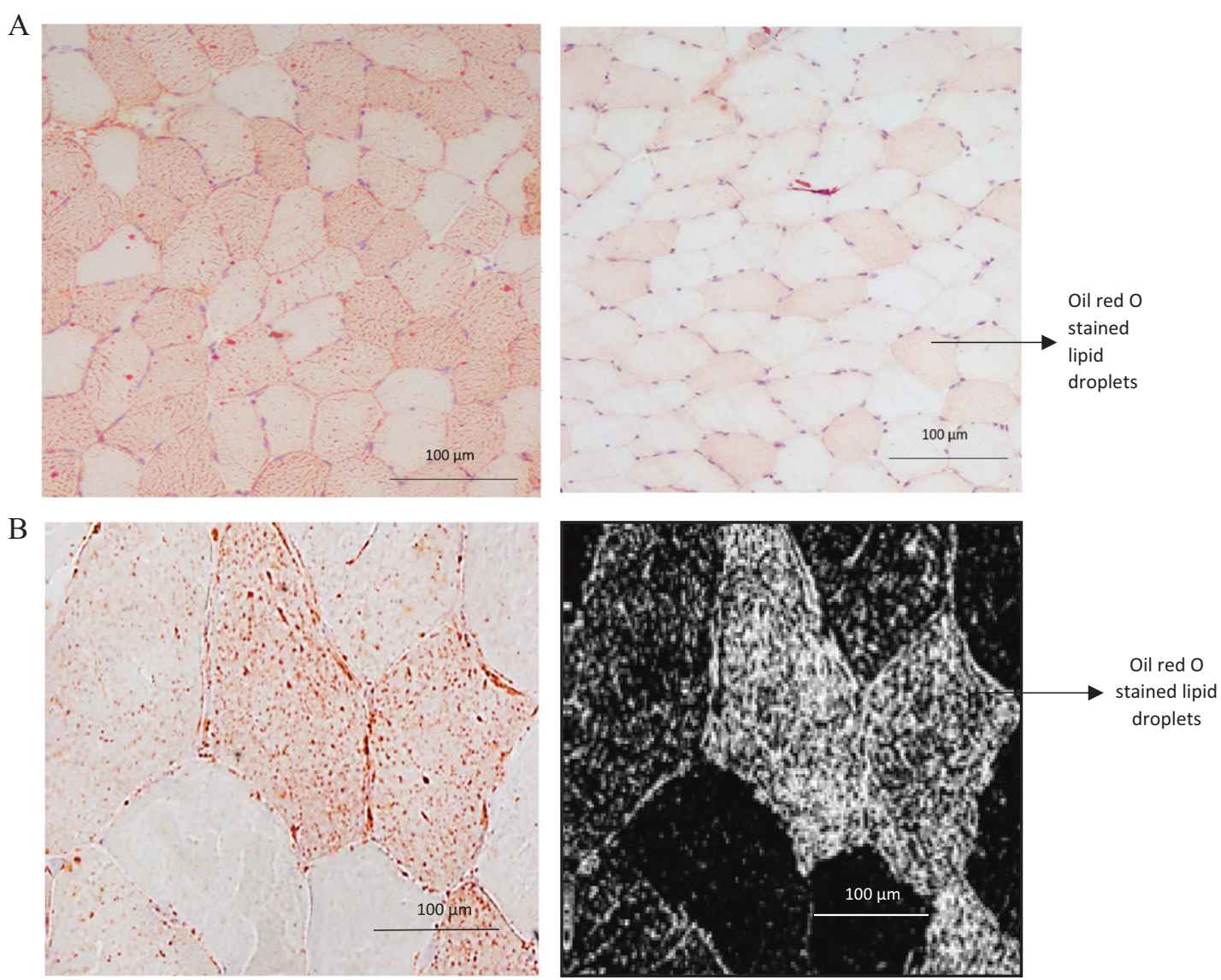

Fig. 1 Oil Red O staining of neutral lipid within skeletal muscle in a representative prediabetes (age, 26 year, left image) and control (age, 21 year, right image) (a). Lipid droplets are viewed as red distinct spots with each image. Tissue quant image analysis of the image as shown in $\mathbf{b}$

for lipid content. The images were analyzed using TissueQuant software (TissueQuant Version 1.0, Manipal, India), for color image segmentation and quantification of fat, as earlier described [29]. Images were also saved as gray-scale images for digitized data analyses, to quantify the IMCL (\% area lipid). The IMCL (\% area lipid) was calculated using average obtained from 5 images per subject. All images underwent double cross checking by two independent observers. Both observers were qualified to read the images. The images were randomly assigned to each observer to confirm that all oil droplets have been picked up by the image analysis software. The IMCL (\% area lipid) was then calculated using by the following formula: Total area occupied by lipid droplets of muscle fiber $\times 100 /$ Total cross-sectional area of a muscle fiber [30].

As fiber type (differentiation of Type 1 from Type 2 fibers) distribution may be important in regard to IMCL content, ATPase histochemistry ( $\mathrm{pH}$ 9.4) was performed on the same muscle biopsy tissue [31]. Fiber type distribution was obtained by counting cells in 5 fields of view which were selected randomly. The fiber type counting was double checked by qualified observers. Due to technical artifacts some samples (prediabetes group $n=3$ and controls $n=1$ ) fiber type composition could not be reliably determined.

\section{Statistics}

Data are presented as mean and standard deviation (SD) or Standard error (SE). Their normality was assessed and comparisons between prediabetes and controls performed using the Independent " $t$ "-test or the Mann-Whitney $U$-test. Analysis of Co-variance (ANCOVA) was performed with age as a covariate. Pearson/Spearman's correlation was used to evaluate association between IMCL and various study parameters. The level of significance was set at $P<0.05$.

\section{Results}

Table 1 represents the descriptive data of the two study groups. The prediabetes group was older than the controls $(P<0.01)$, but otherwise, the groups were comparable in terms of their level of physical activity, lipid profile (cholesterol, LDL, HDL, triglycerides) basal glucose, insulin 
and C-Peptide levels. Appendicular muscle mass, lean mass, percent body fat, central adiposity, waist hip ratio and the whole-body muscle to fat ratio were also comparable between the two study groups, even after controlling for age (Table 1). Maximal isometric and isokinetic torque of the knee extensor muscle was similar between the prediabetes and control groups. After adjusting for age only maximal isometrc torque was significantly higher in the control group $(P=0.03)$. ALMI indices indicated similar values between the prediabetes and control groups $(10.8 \pm 0.6 \mathrm{vs}$. $10.6 \pm 1.0)$.

For the OGTT, peak plasma glucose was higher in participants with prediabetes $(189.0 \pm 41.4 \mathrm{mg} / \mathrm{dl})$ compared to their healthy controls $\quad(156.5 \pm 24.0 \mathrm{mg} / \mathrm{dl}, \quad P<0.01)$ whereas peak insulin values $(159.4 \pm 106.1 \mu \mathrm{U} / \mathrm{ml}$ in prediabetes vs. $190.8 \pm 117.8 \mu \mathrm{U} / \mathrm{ml}$ in controls, $P>0.05)$ and peak C-peptide values $(14.2 \pm 4.3 \mathrm{ng} / \mathrm{ml}$ in prediabetes vs. $19.7 \pm 19.0 \mathrm{ng} / \mathrm{ml}$ in controls, $P>0.05$ ) were comparable between the two study groups. The HbAlc concentration was significantly higher in the prediabetes group. The HOMA-\% B, HOMA-IR and peak insulin secretion rates derived using deconvolution methods were comparable between the two study groups (Table 1).

Examination of fiber type distribution (average number of cells counted, $52.5 \pm 7.9$ cells) revealed that the fraction of type 1 fibers were similar between controls $(42.6 \pm 9.3 \%)$ compared to prediabetes $(41.8 \pm 9.2 \%)$.

An example of Oil Red O staining between an individual with prediabetes and a representative healthy control is represented in Fig. 1. Figure 2a represents the individual and average IMCL content (\%). The average IMCL (\%) was significantly higher in the prediabetes group compared to controls $(7.0 \pm 0.7 \%$ vs. $2.0 \pm 0.3 \%, P<0.001)$.

There was a positive correlation between IMCL (\%) and age when all participants (controls and prediabetes) were included (Spearman's rank correlation coefficient, $\rho=0.5$, $P<0.001)$. When examined separately within groups the prediabetes population did not demonstrate any correlation between age and IMCL (\%) (Fig. 2b, both $\rho<0.1$ and $P=$ $0.98)$. It was observed that age had a non-linear association with IMCL in the control group alone $\left(R^{2}=0.551, P=\right.$ 0.005). The difference in IMCL between groups was adjusted for age in an analysis of covariance (with age as the covariate) was statistically significant at $P<0.001$ (Adjusted marginal means of IMCL were $7.0 \%$ vs. $2.1 \%$ in prediabetic and control groups, respectively). However, age could not be identified as an effect modifier in the comparison between group and IMCL as the interaction of age and group was not statistically signficant.

There was a significant positive association between HbAlc and IMCL fat content (\%) (partial correlation coefficient $=0.53, \quad P=0.005)$, after adjusting for age. HOMA-IR was associated positively and significantly
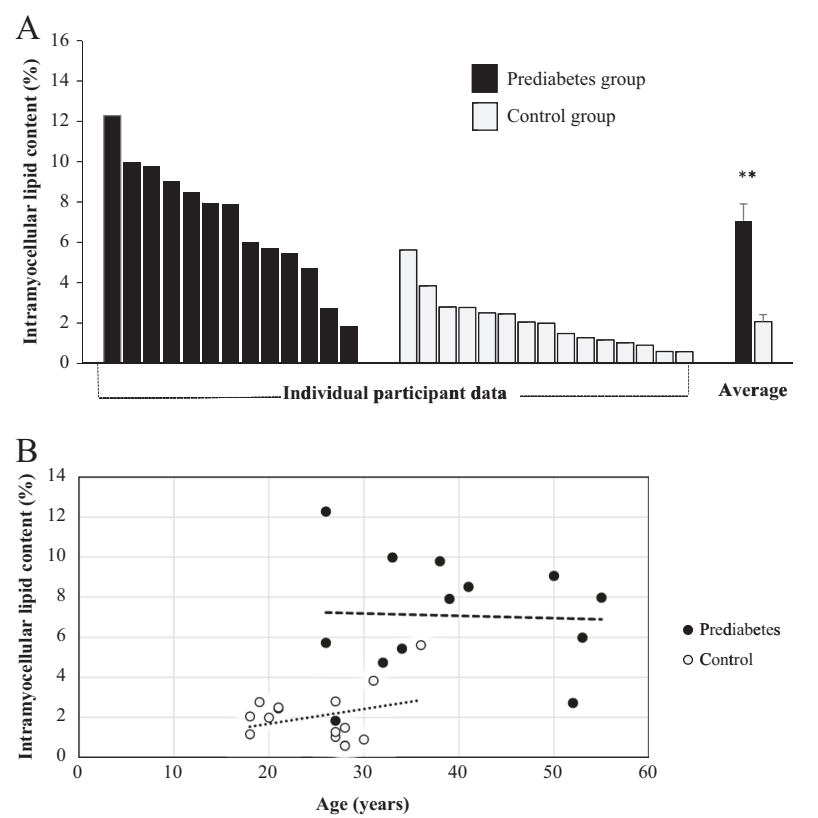

Fig. 2 a Intramyocellular content of individual participants and average (SE) data between the prediabetes and control groups. b The relationship between age and IMCL content. No association was observed with the pre diabetes group (long dashed line), but a significant association was observed in the controls (short dashed line, $P$ $=0.005)$. SE, Standard error. $* * P<0.01$

associated with central adiposity (Table 2) but not with IMCL fat content (\%).

\section{Discussion}

The present study provides the first direct evidence of the presence of a greater intramyocellular fat content among a population of young Indians which contained both normal and overweight indivdiduals with prediabetes compared to healthy controls. This was despite having similar body composition characteristics and levels of physical activity.

The evaluation of the IMCL content involves digital capturing of images with either manual scoring [32] or software based quantitative image analysis [30,33] yielding the percentage of the area occupied by the lipids. Using similar quantitive methods to that described [30, 33], the data reported in the present study show values that are much higher than previously reported. For instance, the IMCL fat content (\%), as measured here was more than two-fold higher than what has been previously observed in sedentary obese with type 2 diabetes from a North American population [30] and three-fold higher than in Type 2 Diabetes patients from a Euopean population [33]. Indeed, healthy Indian controls had an IMCL fat content (\%) that was comparable to the overweight and Type 2 diabetes individuals as reported by Van Loon et al. [33]. These 
Table 2 Representing the correlation matrix between various study variables $(n=28)$

\begin{tabular}{|c|c|c|c|c|c|c|c|c|}
\hline & IMCL $(\%)$ & Central adiposity $(\mathrm{kg})$ & Waist hip ratio & HOMA-IR & HOMA-\%B & HbAlc (g \%) & serum cholesterol $(\mathrm{mg} / \mathrm{dl})$ & $\mathrm{HDL}(\mathrm{mg} / \mathrm{dl})$ \\
\hline Central adiposity (kg) & 0.15 & & & & & & & \\
\hline Waist hip ratio & 0.21 & $0.76 * *$ & & & & & & \\
\hline HOMA-IR & 0.18 & $0.71 * *$ & $0.66 * *$ & & & & & \\
\hline НОМА- $\%$ B & -0.15 & $0.64 * *$ & $0.46^{*}$ & $0.76^{* *}$ & & & & \\
\hline HbAlc $(\mathrm{g} \%)$ & $0.75 * *$ & 0.14 & 0.23 & 0.18 & -0.23 & & & \\
\hline Serum cholesterol $(\mathrm{mg} / \mathrm{dl})$ & -0.25 & 0.02 & -0.31 & -0.15 & -0.09 & -0.19 & & \\
\hline $\mathrm{HDL}(\mathrm{mg} / \mathrm{dl})$ & -0.13 & $-0.46^{*}$ & $-0.57^{* *}$ & $-0.56^{* *}$ & $-0.40^{*}$ & -0.25 & $0.54 * *$ & \\
\hline Serum Triglyceride $(\mathrm{mg} / \mathrm{dl})$ & -0.15 & $0.62 *$ & $0.45^{*}$ & $0.50^{* *}$ & $0.40^{*}$ & 0.04 & 0.22 & $-0.37 *$ \\
\hline
\end{tabular}

$I M C L$ intramyocellular lipid, HbAlc glycated hemoglobin, HOMA-IR homeostatic model assessment-insulin resistance, HOMA \% B homeostatic model assessment-beta cell function, $H D L$ high density lipoprotein, $k g$ Kilogram, $g$ Gram, $m g$ Milligram, $d l$ Deciliter

$* P<0.05, * * P<0.01$

comparisons suggest that Indians have proportionately higher intramyocellular lipid content.

The association of insulin resistance with adiposity in particular central adiposity has been well characterized [5]. Equally the ectopic fat association (for instance IMCL fat content) with insulin resistance has been characterized [34, 35]. The present data set demonstrated a strong association between insulin resistance and central adiposity. However, we did not find any association between IMCL fat content in the quadriceps muscle and insulin resistance. A lack of association between IMCL fat content and insulin resistance has also been reported earlier while comparing various ethnic groups (European Americans vs. African Americans) [36], non-diabetic South Asian vs. Caucasian men [12], as well as in one of the largest cross-sectional comparison studies using ${ }^{1} \mathrm{H}$-magnetic resonance spectroscopy to determine the lipid content in the soleus and tibialis anterior muscles of caucasians [37]. The potential reasons for the lack of association between insulin sensitivity and IMCL content in the present study could be due to possible elevation of intramyocellular fatty acid metabolites such as diacyl-glycerol (DAG), fatty acyl coenzyme A and ceramides which could reduce the insulin-induced tyrosine phosphorylation of the insulin receptor and phosphatidylinositol 3-kinase activity [38]. The location of these metabolites (sarcolemma membrane, sarcoplasmic reticulum, lipid droplets, and mitochondrial membrane) and type of the DAG (1,3-DAG and 1,2-DAG) might play key role the regulation of the insulin sensitivity [39]. Intramuscular lipid could also be compartmentalized differently, for instance IMCL accumulation in the skeletal muscle could show a storage pattern which is characterized by lipid in droplets adjacent to the mitochondria, presumably providing with an enhanced ability to utilize the lipid as substrate as seen studies on trained atheletes [40]. On other hand IMCL could be more subsarcolemmal [41]. Whether different compartmentalization of lipids could explain the observed lack of relationship between IMCL and insulin sensitivity remains to be determined. The DAG stereoisomers, 1,3-DAG and
1,2-DAG, are suggested to influence muscle insulin resistance in different degrees [42]. Only 1,2-DAG has been associated with insulin signaling and and not 1,3-DAG [43]. With a majority of studies only examining whole-muscle DAG concentration, further research is needed in regard to understansing any relationships between insulin resistance and IMCL. Finally, the role of periliphin 5 (PLIN5 is a lipid droplet coat protein with a putative role in liberating fatty acids for oxidative degradation in mitochondria) needs to be considered [44]. PLIN5 is considered to fine tune lipid oxidation to the metabolic demand and considered to protect against lipotoxicity in skeletal muscle [45]. Recent evidence has emerged that PLIN5-coated lipid droplets are positively associated with oxidative capacity, but not with insulin sensitivity [45]. This suggests that future studies should also include analysis of PLIN5 in investigations into the regulation of insulin sensitivity in Indians.

IMCL accumulation has been associated with increasing age [46]. However, it remains to be determined to what extent perturbations in IMCL metabolism are primarly related to the ageing process per se or secondarily to agerelated changes in lifestyle. Chee et al. [47] demonstrated that by matching young and older volunteers for body composition and self-reported habitual physical activity levels, older individuals displayed comparable IMCL content to their younger counterparts. However, age related blunting of free fatty acid oxidation and increased IMCL accumulation as a result of reduced muscle mitochondrial content and oxidative capacity, coupled to decreased levels of physical activity could explain partly the age related accumulation of IMCL [47, 48]. In the present study there was an association between age and IMCL content (\%) when all participants were considered. However, separating into the two groups, a significant association was only observed in the control group. Further analysis also indicated that age could not be identified as an effect modifier in the comparison between study groups and IMCL content (\%). At this stage, with the present study small numbers, it can only be speculative to suggest that alterations in IMCL 
kinetics especially among the prediabetes population might be overlaid on the ageing effect.

There was a strong association between $\mathrm{HbAlc}$ and IMCL content (\%), which could be only speculated as being a reflection of poor glycemic status at this stage. The lack of association might be simply due to the technique adapted to assess insulin sensitivity in the present study like HOMA than euglycemic hyperinsulinemic clamp.

A study spanning Europeans and African-Caribbeans found that waist circumference had the highest impact among several metabolic measures on glucose tolerance [49]. The subcutaneous abdominal fat was strongly and independently correlated to insulin sensitivity [50]. Therefore, while mounting evidence links central adiposity to insulin resistance and the metabolic syndrome trait, it is uncertain whether this relationship is predominantly driven by central or subcutaneous adipose tissue or a combination of the two. The concept of lipodystrophy needs to be further explored among Indians in whom there could be impaired ability to store subcutaneous fat, and consequently with even modest weight gain, the ability to accumulate fat in visceral tissues might be greater (for example, in the muscle or liver). This in turn could lead into marked insulin resistance. This emphasizes the potential role of ectopic fat in the pathophysiology of Type 2 diabetes among Indians especially among normal to overweight individuals.

Of the limited literature available related to fat and Type 2 diabetes among Indians, the only reported study is from a North Indian population, in whom IMCL content in Type 2 diabetes was assessed using ${ }^{1} \mathrm{H}$ magnetic resonance spectroscopy (MRS) of the soleus muscle, and was found to be higher compared to healthy controls [15]. This is in line with the data from the present study among the young prediabetes.

The oxidative skeletal muscle fiber type 1 , displays a greater IMCL content than fiber type 2 [32]. To eliminate the role of fiber type contribution towards the IMCL we also performed ATP ase staining to differentiate the fiber types. There was no difference in \% Type 1 and 2 fibers between the groups, but interestingly the data in both groups towards a faster, less oxidative phenotype as evidenced by the greater proportion of type 2 fibers. Whilst variability exists between individuals, the vastus lateralis is usually consider a mixed ( 50:50) muscle. Furthermore, as all the participants from the present study were either sedentary or only moderately active, it is unlikely that IMCL content to be higher due to their physical activity status [33].

One of the limitations of the present study was the age difference between the prediabetes and control study group. It would have been ideal to match the prediabetes to their age matched controls. However, recruiting healthy middle aged volunteers was challenging, particularly for consenting to the muscle biopsy.
In summary, the present study provides evidence of the existence of markedly higher levels of intramyocellular lipid among Indians with prediabetes compared to healthy controls. Further studies are required to evaluate the mechanisms and reversibility of IMCL with lifestyle intervention programs like the exercise and diet.

Acknowledgements This work was supported by the Wellcome Trust/ DBT India Alliance Fellowship [grant number IA/I/13/1/500907] awarded to Dr. Sucharita Sambashivaiah. Authors would like to thank Dr. Anthea Rowlerson for her constant inputs during the histopathological staining and interpretation. We would like to thank Ms. Nidhi Sharma in coordinating the study. Dr. Gayathri Narayanappa for helping us standardize the stains. Mr Lourdu Swamy for histopathological staining. Also thank Dr. Kishore Bhat for the insulin secretion rates calculations.

Author contributions SS was part of the conception and design, performance of the measurements and analyses, interpretation of the data and drafted the manuscript. AVK and SH were part of conception and design, interpretation of data, writing of manuscript, final approval of manuscript. PR was involved in performance of measurements and analyses, CM was involved in histopathological staining and analyses, $\mathrm{KP}$ was involved in image analysis and interpretation, RLJ and MKP were involved in muscle biopsy and tissue processing. BG and VHM were involved in screening, recruitment of subjects and manuscript preparation. TT and RJB were involved in analyses.

\section{Compliance with ethical standards}

Conflict of interest The authors declare that they have no conflict of interest.

Publisher's note: Springer Nature remains neutral with regard to jurisdictional claims in published maps and institutional affiliations.

Open Access This article is licensed under a Creative Commons Attribution 4.0 International License, which permits use, sharing, adaptation, distribution and reproduction in any medium or format, as long as you give appropriate credit to the original author(s) and the source, provide a link to the Creative Commons license, and indicate if changes were made. The images or other third party material in this article are included in the article's Creative Commons license, unless indicated otherwise in a credit line to the material. If material is not included in the article's Creative Commons license and your intended use is not permitted by statutory regulation or exceeds the permitted use, you will need to obtain permission directly from the copyright holder. To view a copy of this license, visit http://creativecommons. org/licenses/by/4.0/.

\section{References}

1. Snehalatha C, Viswanathan V, Ramachandran A. Cutoff values for normal anthropometric variables in Asian Indian adults. Diabetes Care. 2003;26:1380-4.

2. Patel SA, Shivashankar R, Ali MK, Anjana RM, Deepa M, Kapoor D, et al. Is the "South Asian Phenotype" Unique to South Asians?: comparing cardiometabolic risk factors in the CARRS and NHANES Studies. Glob Heart. 2016;11:89-96. 
3. Raji A, Seely EW, Arky RA, Simonson DC. Body fat distribution and insulin resistance in healthy Asian Indians and Caucasians. $\mathbf{J}$ Clin Endocrinol Metab. 2001;86:5366-71.

4. Banerji MA, Faridi N, Atluri R, Chaiken RL, Lebovitz HE. Body composition, visceral fat, leptin and insulin resistance in Asian Indian men. J Clin Endocrinol Metab. 1999;84:137-44.

5. Ramachandran A, Snehalatha C, Viswanathan V, Viswanathan M, Haffner SM. Risk of noninsulin dependent diabetes mellitus conferred by obesity and central adiposity in different ethnic groups: a comparative analysis between Asian Indians, Mexican Americans and Whites. Diabetes Res Clin Pract. 1997;36:121-5.

6. Sattar N, Gill JM. Type 2 diabetes as a disease of ectopic fat? BMC Med. 2014;26:12:123.

7. Snel M, Jonker JT, Schoones J, Lamb H, De Roos A, Pijl H. et al. Ectopic fat and insulin resistance: pathophysiology and effect of diet and lifestyle interventions. Int J Endocrinol. 2012;2012:1-18.

8. Borén J, Taskinen MR, Olofsson SO, Levin M. Ectopic lipid storage and insulin resistance: a harmful relationship. J Intern Med. 2013;274:25-40.

9. Kurpad AV, Varadharajan KS, Aeberli I. The thin-fat phenotype and global metabolic disease risk. Curr Opin Clin Nutr Metab Care. 2011;14:542-7.

10. George AM, Jacob AG, Fogelfeld L. Lean diabetes mellitus: an emerging entity in the era of obesity. World $\mathrm{J}$ Diabetes. 2015;6:613-20.

11. Mohan V. Why are Indians more prone to diabetes? J Assoc Physicians India. 2004;52:468-74.

12. Forouhi NG, Jenkinson G, Thomas EL, Mullick S, Mierisova S, Bhonsle U, et al. Relation of triglyceride stores in skeletal muscle cells to central obesity and insulin sensitivity in European and South Asian men. Diabetologia. 1999;42:932-5.

13. Rattarasarn C. Dysregulated lipid storage and its relationship with insulin resistance and cardiovascular risk factors in non-obese Asian patients with type 2 diabetes. Adipocyte. 2018;7:1-10.

14. Sinha S, Misra A, Rathi M, Kumar V, Pandey RM, Luthra K, et al. Proton magnetic resonance spectroscopy and biochemical investigation of type 2 diabetes mellitus in Asian Indians: observation of high muscle lipids and C-reactive protein levels. Magn Reson Imaging. 2009;27:94-100.

15. Misra A, Sinha S, Kumar M, Jagannathan NR, Pandey RM. Proton magnetic resonance spectroscopy study of soleus muscle in non-obese healthy and Type 2 diabetic Asian Northern Indian males: high intramyocellular lipid content correlates with excess body fat and abdominal obesity. Diabet Med. 2003;20:361-7.

16. WHO Expert Consultation. Appropriate body-mass index for Asian populations and its implications for policy and intervention strategies. Lancet. 2004;363:157-63.

17. Chamberlain JJ, Rhinehart AS, Shaefer CF Jr, Neuman A. Diagnosis and management of diabetes: synopsis of the 2016 American Diabetes Association Standards of Medical Care in Diabetes. Ann Intern Med. 2016;164:542-52.

18. Vaz M, Bharathi AV, Thomas T, Yusuf S, Kurpad AV. The repeatability of self-reported physical activity patterns in rural South India. Asia Pac J Clin Nutr. 2009;18:71-75.

19. Aguer C, Mercier J, Man CY, Metz L, Bordenave S, Lambert K, et al. Intramyocellular lipid accumulation is associated with permanent relocation ex vivo and in vitro of fatty acid translocase (FAT)/CD36 in obese patients. Diabetologia. 2010;53:1151-63.

20. Barrett-Connor E. The oral glucose tolerance test, revisited. Eur Heart J. 2002;23:1229-31.

21. Faerch K, Pacini G, Nolan J, Hansen T, Tura A, Vistisen D. Impact of glucose tolerance status, sex, and body size on glucose absorption patterns during OGTTs. Diabetes Care. 2013;36:3691-7.

22. Cobelli C, Pacini G. Insulin secretion and hepatic extraction in humans by minimal modeling of C-peptide and insulin kinetics. Diabetes. 1988;37:223-31.
23. Matthews DR, Hosker JP, Rudenski AS, Naylor BA, Treacher DF, Turner RC. Homeostasis model assessment: insulin resistance and B-cell function from fasting plasma glucose and insulin concentrations in man. Diabetologia. 1985;28:412-9.

24. Kuriyan R, Thomas T, Ashok S, Jayakumar J, Kurpad AV. A 4compartment model based validation of air displacement plethysmography, dual energy X-ray absorptiometry, skinfold technique and bio-electrical impedance for measuring body fat in Indian adults. Ind J Med Res. 2014;139:700-7.

25. Kwon HJ, Ha YC, Park HM. The reference value of skeletal muscle mass index for defining the Sarcopenia of women in Korea. J Bone Metab. 2015;22:71-75.

26. Metter EJ, Lynch N, Conwit R, Lindle R, Tobin J, Hurley B. Muscle quality and age: cross-sectional and longitudinal comparisons. J Gerontol Biol Sci. 1999;54A:B207-B218.

27. Shanely RA, Zwetsloot KA, Triplett NT, Meaney MP, Farris GE, Nieman DC. Human skeletal muscle biopsy procedures using the modified Bergström technique. J Vis Exp. 2014;10:51812.

28. Mehlem A, Hagberg CE, Muhl L, Eriksson U, Falkevall A. Imaging of neutral lipids by oil red $\mathrm{O}$ for analyzing the metabolic status in health and disease. Nat Protoc. 2013;8:1149-54.

29. Prasad K, P BK, Chakravarthy M, Prabhu G. Applications of 'TissueQuant'- a color intensity quantification tool for medical research. Comput Methods Prog Biomed. 2012;106:27-36.

30. Goodpaster BH, He J, Watkins SC, Kelley DE. Skeletal muscle lipid content and insulin resistance: evidence for a paradox in endurance-trained athletes. J Clin Endocrinol Metab. 2001;86:5755-61.

31. Hintz CS, Coyle EF, Kaiser KK, Chi MM, Lowry OH. Comparison of muscle fibre typig by quantitative enzyme assays and by myosin ATPase staining. J Histochem Cytochem. 1984;32:655-60.

32. Greco AV, Mingrone G, Giancaterini A, Manco M, Cinti S, Granzotto M, et al. Insulin resistance in morbid obesity: reversal with intramyocellular fat depletion. Diabetes. 2002;51:144-51.

33. van Loon LJ, Koopman R, Manders R, van der Weegen W, van Kranenburg GP, Keizer HA. Intramyocellular lipid content in type 2 diabetes patients compared with overweight sedentary men and highly trained endurance athletes. Am J Physiol. 2004;287:E558E565.

34. Pan DA, Lillioja S, Kriketos AD, Milner MR, Baur LA, Bogardus C. Skeletal muscle triglyceride levels are inversely related to insulin action. Diabetes. 1997;46:983-8.

35. Jacob S, Machann J, Rett K, Brechtel K, Volk A, Renn W. Association of increased intramyocellular lipid content with insulin resistance in lean nondiabetic offspring of type 2 diabetic subjects. Diabetes. 1999;48:1113-9.

36. Ingram K, Lara-Castro C, Gower B, Makowsky R, Allison D, Newcomer B, et al. Intramyocellular lipid and insulin resistance: differential relationships in European and African Americans. Obesity. 2011;19:1469-75.

37. Thamer C, Machann J, Bachmann O, Haap M, Dahl D, Wietek B, et al. Intramyocellular lipids: anthropometric determinants and relationships with maximal aerobic capacity and insulin sensitivity. J Clin Endocrinol Metab. 2003;88:1785-91.

38. Timmers S, Schrauwen P, de Vogel J. Muscular diacylglycerol metabolism and insulin resistance. Physiol Behav. 2008;94:24251.

39. Li Y, Xu S, Zhang X, Yi Z, Cichello S. Skeletal intramyocellular lipid metabolism and insulin resistance. Biophys Rep. 2015;1:9098 .

40. Dube JJ, Amati F, Stefanovic-Racic M, Toledo FG, Sauers SE, Goodpaster BH. Exercise-induced alterations in intramyocellular lipids and insulin resistance: the athlete's paradox revisited. Am J Physiol Endocrinol Metab. 2008;294:E882-888.

41. Nielsen J, Mogensen M, Vind BF, Sahlin K, Hojlund K, Schroder HD. Increased subsarcolemmal lipids in type 2 diabetes: effect of 
training on localization of lipids, mitochondria, and glycogen in sedentary human skeletal muscle. Am J Physiol Endocrinol Metab. 2010;298:E706-713.

42. Turinsky J, O'Sullivan DM, Bayly BP. 1,2-Diacylglycerol and ceramide levels in insulin-resistant tissues of the rat in vivo. J Biol Chem. 1990;265:16880-5.

43. Boni LT, Rando RR. The nature of protein kinase $\mathrm{C}$ activation by physically defined phospholipid vesicles and diacylglycerols. J Biol Chem. 1985;260:10819-25.

44. Kimmel AR, Sztalryd C. Perilipin 5, a lipid droplet protein adapted to mitochondrial energy utilization. Curr Opin Lipidol. 2014;25:110-7.

45. Laurens C, Bourlier V, Mairal A, Louche K, Badin PM, Mouisel E, et al. Perilipin 5 fine-tunes lipid oxidation to metabolic demand and protects against lipotoxicity in skeletal muscle. Sci Rep. 2016;6:38310.

46. Crane JD, Devries MC, Safdar A, Hamadeh MJ, Tarnopolsky MA. The effect of aging on human skeletal muscle mitochondrial and intramyocellular lipid ultrastructure. J Gerontol A Biol Sci Med Sci. 2010;65A:119-28.

47. Chee C, Shannon CE, Burns A, Selby AL, Wilkinson D, Smith K, et al. Relative contribution of intramyocellular lipid to whole-body fat oxidation is reduced with age but subsarcolemmal lipid accumulation and insulin resistance are only associated with overweight individuals. Diabetes. 2016;65:840-50.

48. Peterson KF, Befroy D, Dufour S, Dziura J, Ariyan C, Rothman DL, et al. Mitochondrial dysfunction in the elderly: possible role in insulin resistance. Science. 2003;300:1140-2.

49. Riste L, Khan F, Cruickshank K. High prevalence of type 2 diabetes in all ethnic groups, including Europeans, in a British inner city: relative poverty, history, inactivity, or 21st century Europe? Diabetes Care. 2001;24:1377-83.

50. Tulloch-Reid MK, Hanson RL, Sebring NG, Reynolds JC, Premkumar A, Genovese DJ, et al. Both subcutaneous and visceral adipose tissue correlate highly with insulin resistance in African Americans. Obes Res. 2004;12:1352-9. 